\title{
The Piedmont flood of November 1994: a testbed of forecasting capabilities of the CNR-ISAC meteorological model suite
}

\author{
Silvio Davolio ${ }^{1}$ (D) Piero Malguzzi ${ }^{1} \cdot$ Oxana Drofa $^{1} \cdot$ Daniele Mastrangelo $^{1}$ • \\ Andrea Buzzi ${ }^{1}$
}

Received: 23 March 2020 / Accepted: 15 July 2020/ Published online: 27 August 2020

(C) Springer Nature Switzerland AG 2020

\begin{abstract}
The celebration of the 25th anniversary of the Piedmont flood was organized by the University of Piemonte Orientale in Alessandria, a town that was severely affected in November 1994. It has been an opportunity to reexamine the meteorological event and assess the potential of CNR-ISAC models, after more than 20 years of development, to accurately simulate the heavy precipitation at different lead times. The predictability of this extreme event has been studied on a wide range of space and time scales, from subseasonal to convection resolving, using a variety of model setups and initial conditions. The subseasonal experiment produces a precipitation anomaly that, even if underestimated, indicates some predictability beyond the second forecast week. At shorter ranges, results indicate that there is a consistent improvement in the precipitation forecast going from low-resolution hydrostatic to high-resolution nonhydrostatic models. It is only at very high resolution $(500 \mathrm{~m})$ that the convective activity extending to the north of the divide line of the Ligurian Apennines, which was responsible for the flood of the Tanaro River, is predicted with an intensity comparable with rain gauge observations. The main mesoscale phenomena that played a role in the different phases of the event have been also identified.
\end{abstract}

Keywords Heavy precipitation · Piedmont flood · Orography $\cdot$ ISAC models $\cdot$ High resolution

\section{Introduction}

The infamous Piedmont flood of 1994 affected a relatively vast area in northwestern Italy, almost entirely contained in the administrative region of Piedmont (Fig. 1). Several rivers

Silvio Davolio

s.davolio@isac.cnr.it

1 National Research Council of Italy, Institute of Atmospheric Sciences and Climate, CNR-ISAC, Via Piero Gobetti 101, 40129 Bologna, Italy 
overflowed their banks, some having their catchment basins in the western Alps, where the chain exhibits its largest concavity, corresponding to northwestern Piedmont. A severe flooding affected also the Tanaro River, whose catchment is located in a different area, between the Ligurian Apennines and the Maritime Alps in the southern portion of Piedmont (see also Fig. 1 in Buzzi et al. 1998 and Fig. 3). Flooding of the former group of rivers was associated with the huge orographic rainfall maximum present on the southeastern flank of the Alpine chain as visible in Fig. 1, with accumulated maxima exceeding $500 \mathrm{~mm}$ in $48 \mathrm{~h}$. Flooding of the Tanaro River was associated with the secondary maximum between the Alps and the Apennines, also visible in Fig. 1, with corresponding observed values of $48 \mathrm{~h}$ accumulated precipitation around $250 \mathrm{~mm}$ (Cassardo et al. 2002).

Although the Piedmont flood was not a flash-type flood, since it was due to rainfall insisting over the same areas for a couple of days (except for high intensity rainfall peaks of shorter duration over the Apennines - see below), it was severely underpredicted, and the alert system underwent a total failure. The disaster revealed the deficiencies in operational meteorological and hydrological monitoring and forecasting at the time. It stimulated a substantial effort, at national and, to a larger extent, regional levels, for the implementation of modern observational networks and, in a second stage, for the development of meteorological and hydrological forecasting systems based on the application of regional numerical models. On the one hand, at the time the European Centre for Medium-range Weather Forecasts (ECMWF) global model had a totally inadequate resolution (T213, corresponding to a grid distance of about $90 \mathrm{~km}$, Branković and Molteni 1997) for an accurate quantitative precipitation forecasting (QPF). On the other hand, development and operational application of higher resolution limited area models in Italy were in its pioneering stage. For example, the development of the BOLAM model had started a few years before the event: the first paper presenting the model (Buzzi et al. 1994) had just been published. The very few nonhydrostatic models available at the time were used only for scientific purposes.
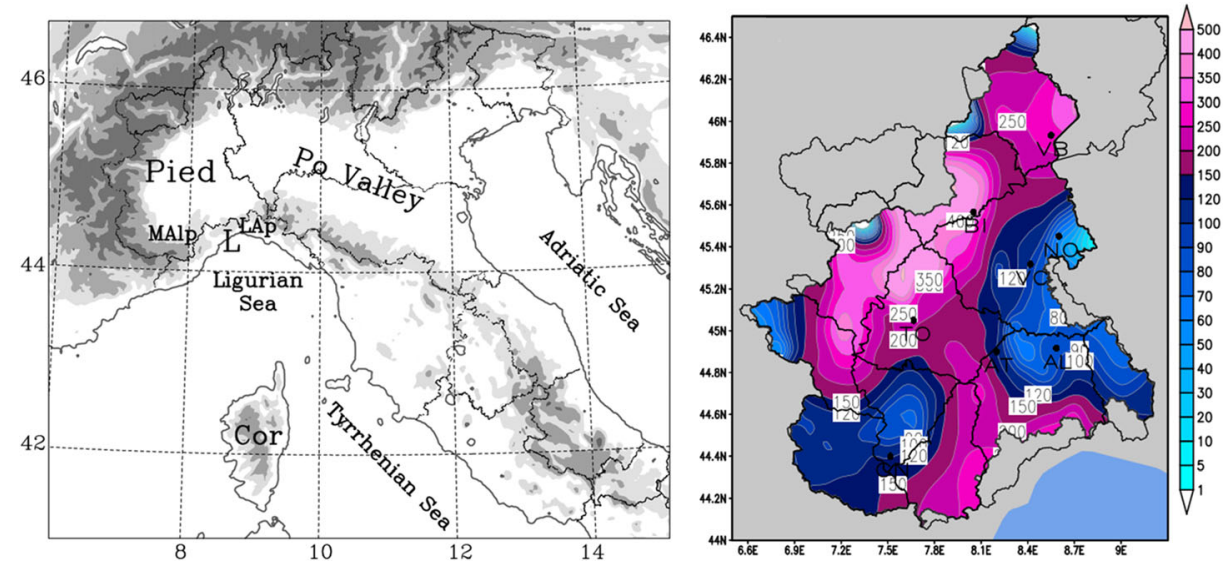

Fig. 1 (Left) Relevant geographical details of the area of interest. "Pied", "L" and "Cor" indicate Piedmont and Liguria regions, and Corsica, respectively. Maritime Alps (MAlp) and Ligurian Apennines (Lap) are indicated. Orography is also plotted using grey shading corresponding to 500, 1000 and $2000 \mathrm{~m}$. Lines indicate region administrative borders. (Right) Total $72 \mathrm{~h}$ observed precipitation (mm) accumulated between 04 and 06 November 1994 over Piedmont region (courtesy of ARPA Piemonte). Black lines indicate province administrative borders; the rainfall field is obtained by interpolation of the regional rain gauge network data and plotted only over the Piedmont region area 
The Piedmont flood of 1994 became a testbed for subsequent projects in the field of dynamical meteorology and meteorological model development, testing the models capability of predict the event and, in particular, the precipitation amount, and for the coupling between meteorological and hydrological models. For example, in the context of the European projects RAPHAEL (Bacchi and Ranzi 2000) and HERA (Volkert 2000), a multimodel investigation of the flood event led to the following results: (a) using the ECMWF analyses as initial conditions, hydrostatic models with a sufficiently high resolution (grid distance of the order of 10-20 km) were capable of a reasonable forecast of the orographic precipitation over the Alps, while (b) the precipitation maximum over the Apennines/Maritime Alps remained underpredicted. In particular, models tended to predict it south of the orographic divide, so that the associated Tanaro River flood could not be adequately represented by hydrological models tested in cascade (Buzzi et al. 1998; Buzzi and Foschini 2000).

A deeper analysis of meteorological model results, and of the causes of their deficiencies, allowed distinguishing the mechanisms associated with the two main precipitation maxima. The main maximum in the western Alps was attributed to orographic lifting in quasi-neutral stratification (taking into account the reduction of static stability in saturated conditions - see Lalas and Einaudi 1974), so convection in this area did not play a basic role. Conversely, multiple convective cells originating over the Ligurian Sea and travelling to the north (Buzzi and Foschini 2000) contributed essentially to the southerly maximum. Consequently, the underforecasting of precipitation amount in the Tanaro River catchment could be attributed to the limited capability of convective parameterization schemes to adequately represent convective precipitation in hydrostatic models. In addition to the latter aspect, it was realized that hydrostatic dynamics (papers quoted above) in the presence of flow over a ridge, as in the case of the Ligurian topography, tend to produce larger amplitude descent associated with the lee wave dynamics. This means that hydrostatic models tend to confine precipitation to the upstream side of a ridge, suppressing it at the divide and downstream. Another model aspect that was found to contribute to the QPF error over the northern side of the Apennines was the lack of advection of falling precipitation (snow in particular), considering that, in cases of strong winds, precipitation can fall tens of $\mathrm{km}$ downstream of the area of formation aloft. Most of the regional models, including BOLAM, implemented advection of hydrometeors at the end of 1990s (see again Buzzi and Foschini 2000; Ferretti et al. 2000).

During the 1990s, a major international research experiment, the Mesoscale Alpine Programme (MAP; Bougeault et al. 2001) was planned, culminating in the observational field phase in 1999. The study of orographic "dry" and "wet" processes associated with orography, addressed to the improvement of weather forecasting in mountainous regions, was the main objective of MAP. The 1994 Piedmont flood event was selected as one of the most significant events in the Alps to be studied, in order to better understand the dynamical and microphysical processes responsible for orographic heavy precipitation, and to improve meteorological models used both in research and forecasting. Some studies of the MAP stage preceding the field campaign led to the formulation of conceptual models that were subsequently confirmed and refined, after the MAP field phase results became available. Among them, Buzzi et al. (1998), by comparing numerical experiments designed to reveal the effects of moist processes on mesoscale dynamics, showed the importance of equivalent (moist) static stability in governing the establishment of flow-over versus flow-around regimes. Such processes, implying very important feedbacks between dynamics and "microphysics" (i.e., moist processes associated with atmospheric condensation and evaporation), were the object of several subsequent studies based on the interpretation and modelling of meteorological events of heavy 
precipitation in the Alpine area, observed during the MAP field phase (see, for example, Rotunno and Ferretti 2001; Rotunno and Ferretti 2003; Bousquet and Smull 2003; Chiao et al. 2004; Lascaux et al. 2006; Richard et al. 2007; Rotunno and Houze 2007).

The topic of heavy precipitation and floods in the Mediterranean area has continued to be of great interest for the scientific community, and it has been the core of the research activities of the Hydrological Cycle in the Mediterranean Experiment (HyMeX, Drobinski et al. 2014) during the last decade. The field campaign in fall 2012 (Ducrocq et al. 2014) was entirely devoted to study the formation of quasi-stationary mesoscale convective systems and their interaction with the complex orography surrounding the basin, in order to advance the scientific knowledge and eventually improve forecasting. Compared with MAP, higher resolution models and improved monitoring facilities and scientific instrumentation allowed investigating the small scales of convection, providing new insights on the physical processes (e.g., Davolio et al. 2016; Pichelli et al. 2017; Lee et al. 2018).

This paper is also an opportunity to provide an overview of the research activity in the field of numerical modelling at the Institute of Atmospheric Sciences and Climate (ISAC) of the National Research Council of Italy (CNR), of its main applications and current operational implementation. The general synoptic situation leading to this severe event is described in the "Weather evolution" section. The ISAC meteorological suite is presented in the "Overview of ISAC models" section. The "Simulation results on different space and time scales" section is devoted to the presentation of the main results achieved by both the monthly ensemble forecasts and the short-term simulations. The "Convection over the Ligurian Sea and related mesoscale phenomena" section describes physical mechanisms responsible for convective initiation during the first phase of the event, and the "Conclusions" section provides summary and concluding remarks.

\section{Weather evolution}

The synoptic situation between 4 and 6 November 1994 (Fig. 2) was typical of Alpine heavy precipitation events in autumn, as identified and described in many papers (see, for example, Buzzi et al. 1998; Massacand et al. 1998; Ferretti et al. 2000; Buzzi et al. 2014; Grazzini et al. 2020): a deep trough over the eastern Atlantic approached the European coast and then deepened over the western Mediterranean basin. The slow eastward progression of the trough and its increasing amplitude, associated with a positive potential vorticity anomaly (streamer) in the upper troposphere, favoured an intensification of geopotential gradient on the eastern side of the trough and, in turn, of the moisture transport towards the Alps, in the form of a prefrontal southerly low-level jet developing over the Tyrrhenian Sea.

Several processes contributing to the event were identified in previous papers: Ferretti et al. (2000) showed that rising motion associated with synoptic-scale ascent was further enhanced by orographic lifting of conditionally unstable air and by latent heat release. Positive vorticity due to vortex stretching produced an easterly perturbation in the wind field over the Po Valley, which slowed the eastward progression of the precipitation system, and induced further lifting of unstable air. Buzzi et al. (1998) identified the critical role of latent heat conversions, associated with moist processes, for the formation of a multiple front-like rainband structure and for determining the orographic flow regime.

Two areas of northwestern Italy were hit by the flood event. Heavy rainfall characterized by intense convective activity was recorder especially over the area where the Maritime Alps join 


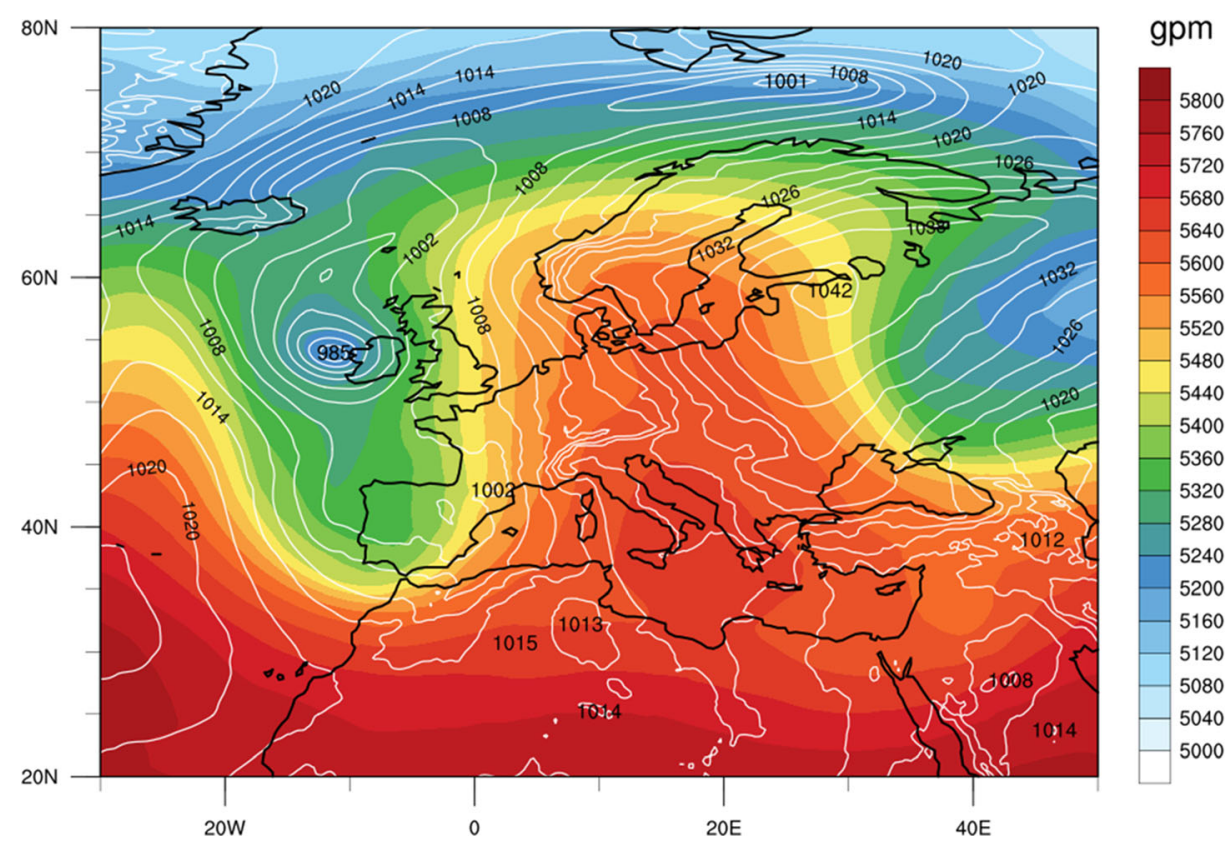

Fig. 2 ECMWF ERA5 reanalysis valid at 1200 UTC, 04 November 1994: 500 hPa Geopotential height (colour shading) and mean sea level pressure (white isolines)

the Ligurian Apennines (hereafter referred to as Apennines) since the afternoon of 4 November (Fig. 1). Rainfall affected both sides of the orography divide, the upwind Liguria catchments as well as the downwind drainage areas of the Po river tributaries (the most important being the Tanaro River, Fig. 3) in southern Piedmont. Later on, during 5 November, a second and more intense precipitation spell affected also the northwestern Alps especially on the upslope area. This spell was mainly ascribed to intense orographic ascent of the prefrontal low-level jet (Buzzi et al. 1998; Cassardo et al. 2002), possibly enhanced by mesoscale mechanisms as described above. Precipitation intensity weakened in the morning of 6 November. Despite the total accumulated precipitation was higher over the Alps, exceeding $350 \mathrm{~mm}$ in $36 \mathrm{~h}$ on a wide area, locally larger than $500 \mathrm{~mm}$, the major floods occurred in southern Piedmont, within watersheds along the northern side of the Apennines. In fact, precipitation was uniformly distributed during the 2 days over the Alps, while it was mostly concentrated in the night between 4 and 5 November over the Apennines. Extensive damages to agriculture, infrastructures and private properties, as well as 70 casualties, were the dramatic, final result of this destructive flood.

\section{Overview of ISAC models}

\subsection{Historical background and applications}

A systematic activity in developing original atmospheric models at ISAC was initiated in the early 1990s. A limited area hydrostatic model (BOLAM, Buzzi et al. 1994) was set up mainly with the purpose of providing a scientific and operational tool for forecasting severe 

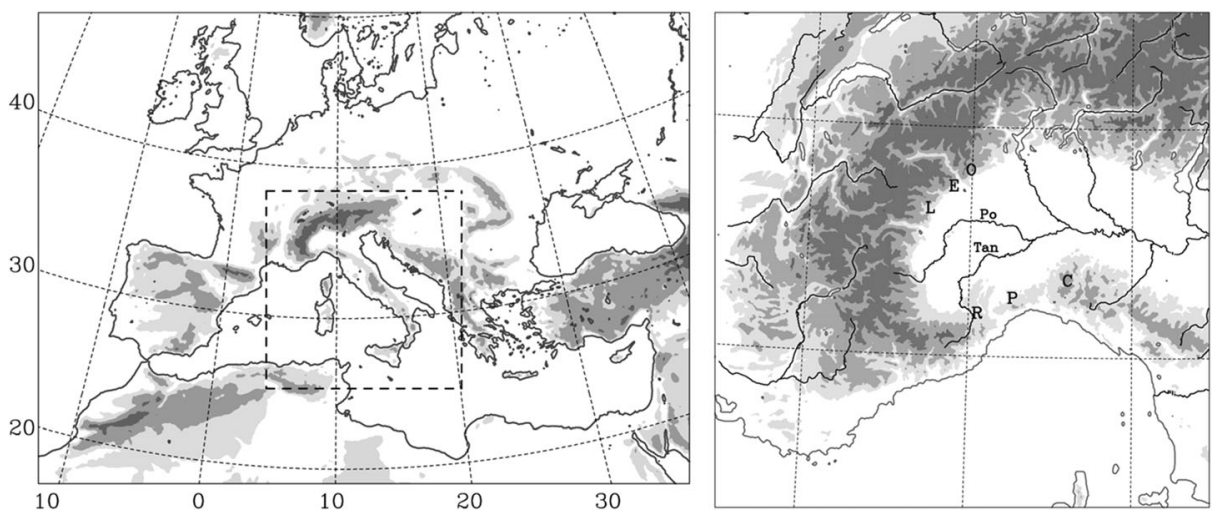

Fig. 3 (Left) Operational integration domain of BOLAM (full image) and MOLOCH (dashed box). (Right) Integration domain for the high-resolution (500 m grid spacing) MOLOCH experiment and indication of the rivers Po and Tanaro (Tan). Rain gauge locations: $\mathrm{C}=$ Capanne di Cosola, $\mathrm{P}=$ Ponzone, $\mathrm{R}=$ Priero, $\mathrm{L}=\mathrm{Lanzo}$, $\mathrm{E}=$ Eugliano and $\mathrm{O}=$ Oropa. In both panels, model orography is also plotted using grey shading corresponding to 500,1000 and $2000 \mathrm{~m}$

meteorological phenomena like heavy precipitation and strong winds over Europe and more specifically over the Mediterranean area. In fact, in that period, after the occurrence of major floods, it became clear also in Italy that limited area models could provide much more accurate short-range forecasts, especially of precipitation, than the global models that were almost the exclusive source of information at the time.

More recently, a non-hydrostatic limited area model (MOLOCH, Malguzzi et al. 2006) was developed as a tool for high resolution (1-3 km grid spacing) forecasting, allowing the explicit treatment of atmospheric convection. Finally, a global atmospheric model (GLOBO, Malguzzi et al. 2011) was also developed at ISAC, based mainly on the equations and parameterization set of BOLAM, using a simplified ocean and sea ice scheme. More recently, BOLAM and GLOBO have been unified in a single code.

The above models are suitable to simulate and predict the atmospheric circulation from the global to the local scale, at different temporal ranges, with high computational efficiency. They have been used for numerous scientific studies and applications, as for instance: sensitivity and impact studies, and diagnostics of meteorological phenomena including severe weather and storms (e.g. Malguzzi et al. 2006; Cavaleri et al. 2010; Fantini et al. 2012; Cioni et al. 2016; Davolio et al. 2016, 2017a; Buzzi et al. 2020); model coupling with hydrological and ocean models (Davolio et al. 2015; Lombardi et al. 2018; Ferrarin et al. 2013, 2019; Poletti et al. 2019); theoretical and idealized studies of instability processes (Davolio et al. 2009; Fantini and Malguzzi 2008); applications to probabilistic and ensemble forecasting, and atmospheric predictability studies (Uboldi and Trevisan 2015; Corazza et al. 2018); data assimilation studies (Tiesi et al. 2016; Davolio et al. 2017b); model validation and intercomparison projects (Nagata et al. 2001; Casaioli et al. 2013). The ISAC NWP models have also been employed as basic tools in many international field experiments such as the international forecasting demonstration project called MAP D-PHASE (Rotach et al. 2009) and the HyMeX campaign SOP1 (Ducrocq et al. 2014; Ferretti et al. 2014), and in numerous European scientific projects.

Besides the scientific applications, ISAC models, specifically BOLAM and MOLOCH, are used for operational forecasting practice by several Italian and foreign institutions (e.g. Lagouvardos et al. 2003; Mariani et al. 2015; Corazza et al. 2018). GLOBO is among the 
models that provide extended range forecasts on the monthly time scale in the context of the Subseasonal-to-Seasonal (S2S) project under the WWRP/WCRP program (Vitart et al. 2017). These model suites are, at present, being operated by ISAC itself under the support of the Italian Civil Protection Department, and meteorological forecasts at different resolutions and time ranges, produced with the three models, are daily publicly available, as described in the following subsection.

\subsection{Models description and operational forecasting implementation}

For the sake of brevity, in the following, only a very synthetic description of the models and of their current operational implementation is provided. For more details, appropriate references will be indicated.

The three models share numerical characteristics, such as the staggered Arakawa $\mathrm{C}$ grid, where prognostic variables are defined, and the three-dimensional advection scheme based on a second-order, weighted-average flux implementation with "superbee" limiter (Hubbard and Nikiforakis 2003). Also the physical schemes are similar, with some adjustments due to the different nature and resolution of the models: boundary layer turbulence (E-1, 1.5 order closure, Zampieri et al. 2005; Trini Castelli et al. 2020), deep convection (Kain 2004, not applied in MOLOCH), radiation (Ritter and Geleyn 1992; Morcrette et al. 2008) and soil and microphysical processes (Buzzi et al. 2014).

GLOBO is a grid-point, hydrostatic, atmospheric general circulation model on a uniform mesh in geographic coordinates on the sphere. Special filtering techniques are applied to deal with the grid singularity near the poles. The sea surface temperature evolution is modelled with a mixed layer ocean. A full description of the dynamics and physics of the model is given in Malguzzi et al. (2011). GLOBO is used at ISAC to produce 7-day global forecasts at the resolution of $19 \mathrm{~km}$ and 60 pressure-based hybrid levels, using NOAA-GFS analysis fields as initial conditions. GLOBO is also employed in a monthly forecasting activity (Mastrangelo and Malguzzi 2019), which makes use of calibrated ensemble forecasts, with initial conditions derived from NOAA-NCEP Global Ensemble Forecasting System. Monthly ensemble predictions at $60-\mathrm{km}$ resolution $(40$ members plus a control run) are released once a week and feed the S2S database.

In the operational version, BOLAM integrates the primitive equations on a latitudelongitude rotated grid at about 8-km horizontal resolution, with 60 pressure-based hybrid levels. BOLAM can be driven by different global models, GFS (NCEP), IFS (ECMWF), GLOBO itself and by other regional models. GLOBO is currently used for the ISAC operational activities to provide initial and boundary conditions for 72-h forecasts over the European domain (Fig. 3). Therefore, GLOBO, BOLAM and MOLOCH are employed in cascade (one-way nesting). BOLAM provides lateral boundary conditions at an appropriate spatial resolution and hourly frequency (although the progressive improvement in horizontal resolution would already allow a direct nesting of MOLOCH into global models). A nesting of MOLOCH into itself is also possible.

MOLOCH can produce forecasts with high spatial detail. In the current ISAC implementation, it integrates the nonhydrostatic, fully compressible equations for the atmosphere, with a grid size of $1.25 \mathrm{~km}$ and 60 height-based hybrid atmospheric levels, and provides 2-day forecasts over a $1154 \times 1154$ grid-point domain covering the whole Italian peninsula and surrounding seas (Fig. 3). 
For more details about both models, see (Malguzzi et al. 2006; Buzzi et al. 2014; Trini Castelli et al. 2020). ISAC operational products are available on the web page http://www.isac. cnr.it/dinamica/projects/forecasts/.

\subsection{Simulations: rationale and setup}

For this study of the Piedmont flood, several experiments are performed in order to test and compare different setups of the forecasting chain that are currently implemented, or represent a possible future operational setup. Moreover, these experiments are designed to provide insights concerning the predictability of this specific event at different scales and temporal ranges, as well as to show the improvement in knowledge and forecasting techniques attained after 25 years.

As far as monthly forecasts are concerned, thanks to the 10-member ensemble available at subdaily frequency, the ERA5 reanalysis dataset (Hersbach and Dee 2016; C3S Copernicus Climate Change Service 2017) is suitable to initialize an ensemble subseasonal hindcast for the Piedmont event. To replicate the operational setup of the ISAC real-time subseasonal forecasts, all ten ERA5 members were selected for each synoptic time of 20 October 1994, and a single member was selected at 0000 UTC, 21 October 1994. The latter is the control member of the 41-member perturbed-lagged ensemble forecast produced with the GLOBO model. Forecast outputs need to be calibrated to reduce the model bias arising along the forecast range. The calibration is obtained by means of the reforecast dataset operationally used in the ISAC subseasonal forecasting system. This dataset is made up of 5-member ensembles initialized with ERA-Interim data (Dee et al. 2011) and covers the 1981-2010 period with a 5-day frequency. The reforecast ensembles initialized on the calendar days close to the forecast initialization date are combined according to the weighted average technique adopted since the early stage of subseasonal forecasting at ISAC (Mastrangelo et al. 2012). The resulting fields are used to produce calibrated forecast anomalies referred to the 19812010 period as in the current operational practice (Mastrangelo and Malguzzi 2019).

As far as short-range forecasts are concerned (Table 1), BOLAM is first run with a configuration mimicking that of the 1990s: although the code is up-to-date and the initial and boundary conditions are provided by modern ERA5 reanalyses every $3 \mathrm{~h}$, horizontal and vertical resolutions are largely decreased to be comparable with the

Table 1 Details and acronyms of the numerical experiments. Every column describes the implementation of a modelling chain, starting from the global reanalysis/model to the high resolution simulation. Initialization times, characteristics of the model grid and acronyms of the experiments (used in the text) are also indicated

\begin{tabular}{|c|c|c|c|c|c|}
\hline Global analyses/model & ERA5 & ERA5 & ERA5 & IFS high res experiment & $\begin{array}{l}\text { GLOBO } \\
\text { (on ERA } \\
\text { interim analysis) }\end{array}$ \\
\hline 04 Nov analysis time & $0000 \mathrm{UTC}$ & $0000 \mathrm{UTC}$ & $1200 \mathrm{UTC}$ & $0000 \mathrm{UTC}$ & 0000 UTC \\
\hline Model & BOLAM & BOLAM & BOLAM & & BOLAM \\
\hline Exp. acronym & BOL-OLD & BOL & BOL12 & & \\
\hline Hor-res, levels & $20 \mathrm{~km}, 30$ & $8 \mathrm{~km}, 60$ & $8 \mathrm{~km}, 60$ & & $8 \mathrm{~km}, 60$ \\
\hline Initialization time & 0000 UTC & 0000 UTC & $1200 \mathrm{UTC}$ & & $1200 \mathrm{UTC}$ \\
\hline Model & & MOLOCH & MOLOCH & MOLOCH & MOLOCH \\
\hline Exp. acronym & & MOL & MOL12 & MOLexp & MOL500 \\
\hline Hor-res, levels & & $1.25 \mathrm{~km}, 60$ & $1.25 \mathrm{~km}, 60$ & $1.25 \mathrm{~km}, 60$ & $0.5 \mathrm{~km}, 60$ \\
\hline Initialization time & & 0300 UTC & 1200 UTC & 0000 UTC & 1200 UTC \\
\hline
\end{tabular}


first BOLAM simulations presented in Buzzi et al. (1998). In another set of simulations, BOLAM and $\mathrm{MOLOCH}$ are run in cascade as in their operational practice, driven by ERA5 reanalyses at 3-h intervals, but starting at two different initial times, $12 \mathrm{~h}$ apart. The fourth experiment consists in a direct nesting of MOLOCH (same operational domain and resolution) into the IFS forecast that has been released by ECMWF with a recent version of the IFS model (45R1, https:/www.ecmwf. int/en/forecasts/documentation-and-support/evolution-ifs/cycles/summary-cycle-45r1) specifically for the study of this flood on its 25 th anniversary. This IFS forecast is available at high horizontal resolution $(9 \mathrm{~km})$ and every $3-\mathrm{h}$, thus making it possible to avoid the intermediate step provided by the BOLAM forecast. Finally, a modelling chain based exclusively on one-way nesting of the three ISAC models is run, starting from ERA-Interim reanalysis and implementing a very high horizontal resolution version of MOLOCH (500 $\mathrm{m}$ of grid spacing). The latter is not currently applied for operational forecasting, due to the insufficient computational resources for a domain covering the whole Italian region. However, this model version has been already tested in several research applications (e.g. Trini Castelli et al. 2020). Its integration domain, smaller than the operational one, is shown in Fig. 3.

\section{Simulation results on different space and time scales}

\subsection{Monthly ensemble forecasts}

The subseasonal prediction performed for this high-impact event aims at giving some indications on the feasibility of forecasting precipitation with the ISAC ensemble forecasting system beyond the second week. Week averaging is usually adopted on the subseasonal scale since it filters out the shorter scale features and highlights the underlying large scale anomaly, which is the achievable goal beyond the limits of deterministic predictability. Among a series of runs initialized to reproduce the target event within the 3rd forecast week that is $15-21$ days in advance, the 41-member perturbed-lagged ensemble initialized on 21 October 1994 predicts heavy precipitation over Northern Italy and is presented in Figs. 4 and 5.

Figure 4 shows the observed weekly precipitation anomaly (as obtained from the ERA5 dataset and referred to the 1981-2010 period) for the period 4-10 November 1994 and the corresponding predicted field. The ISAC monthly forecasting system substantially captures the main precipitation maxima in the Mediterranean area more than 2 weeks in advance, although the main peak over northern Italy is underestimated and displaced too much to the east. This
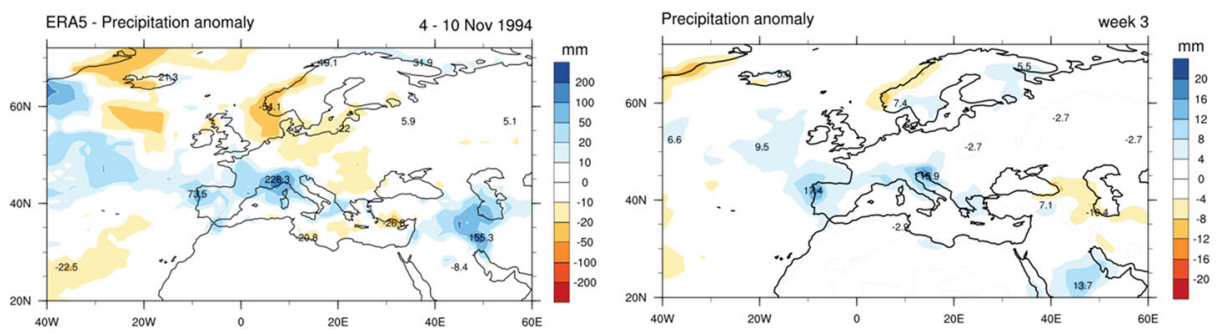

Fig. 4 Observed (left) and predicted (right, third week) precipitation anomaly for the period 4-10 November 1994 

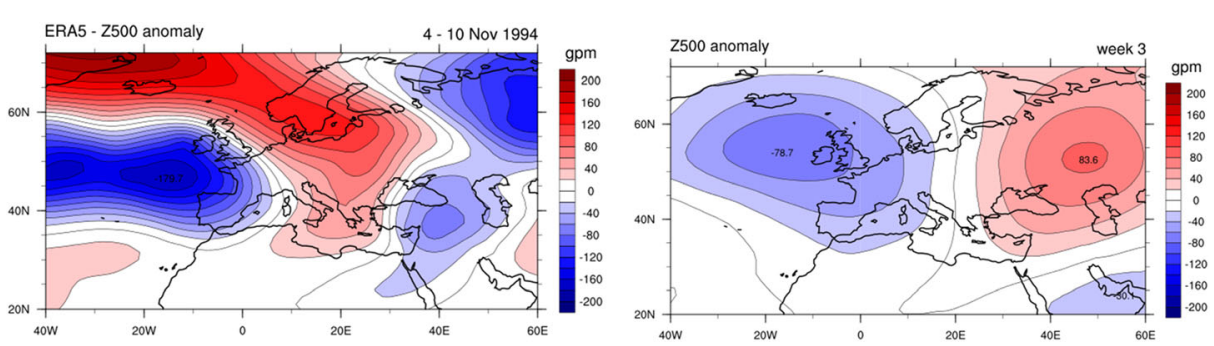

Fig. 5 Same as Fig. 4, but for the 500-hPa geopotential height (contour interval 20 gpm)

misplacement has a counterpart in the forecast $500-\mathrm{hPa}$ geopotential anomaly over the same period (Fig. 5). In fact, the edge between the low- and high-pressure anomalies over the Mediterranean, and therefore, the associated anomalous moist meridional flux is shifted eastward and is more southwest-northeast oriented than the observed one. Nonetheless, this is an indication that precipitation, even in extreme events, can attain some degree of predictability from the larger scale environment, here represented by the geopotential field. On the subseasonal scale, this is expected especially for persistent anomalies (Vitart et al. 2019), although, in this case, the rainy event lasted only a couple of days.

Finally, Fig. 6 shows an example of forecast of precipitation probability for the same forecast week (4-10 November 1994). The probability that predicted precipitation falls in the upper tercile of the precipitation distribution of the 1981-2010 reforecasts turns out to be higher than the climatological value and in excess of 50\% in some places over northern Italy.

Within the limits of a single case study, and although barely successful, the results obtained for this high-impact event suggest the potential role of subseasonal forecasting in the context, for instance, of civil protection: to provide a timely information for an early stage alert system that precedes the activation stage, the latter relying mainly upon higher-resolution, short-term forecasts (White et al. 2017).

upper tercile forecast probability (\%)

week 3

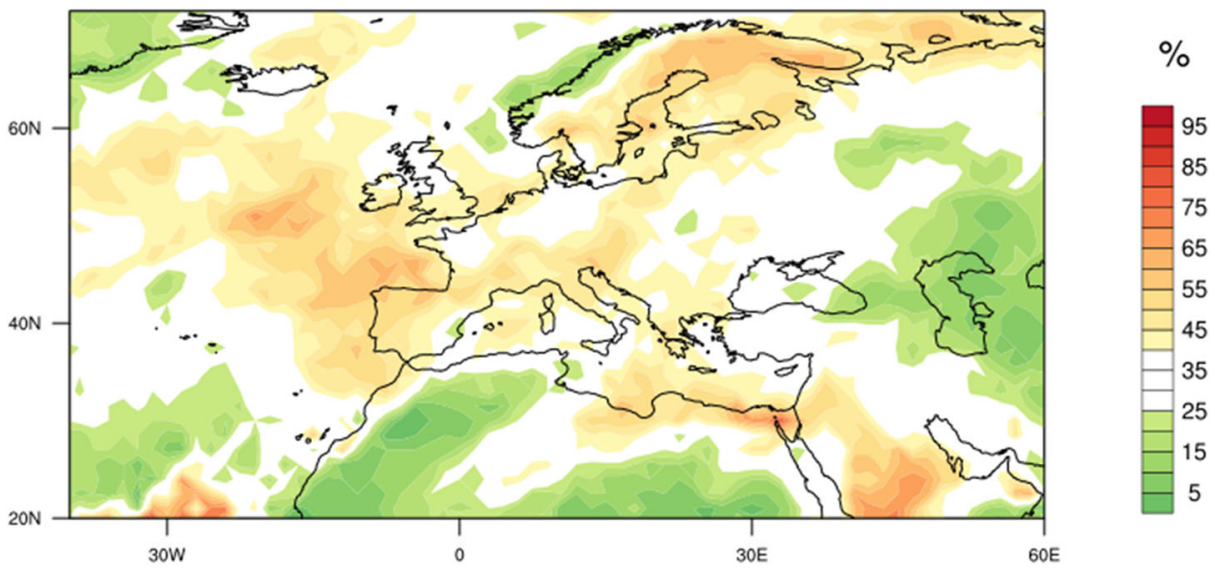

Fig. 6 Upper tercile forecast probability for week 3, valid for the accumulated precipitation in the period 4-10 November 1994 


\subsection{Short-range simulations: impact of resolution and of different setup}

As described in Buzzi et al. (1998) and Rotunno and Ferretti (2001), in the Piedmont flood of 1994, moist flow interaction with orography played a critical role at different scales of motion and determined the location and intensity of precipitation. While rainfall over the Alps was quite well predicted (see Fig. 10 in Buzzi et al. 1998 and Fig. 5 in Ferretti et al. 2000), the largest forecast error was identified on southern Piedmont (also by Cassardo et al. 2002), in the lee side of the Apennines, where the forecast precipitation maximum, associated with convection, was misplaced several tens of $\mathrm{km}$ to the south, towards the coast. The authors speculated that at least part of the error could be due to the lack in the numerical models of explicit representation of the convective cells drifting northward.

A comparison between BOL-OLD and BOL00 (see Table 1) simulations (Fig. 7) clearly shows that a grid spacing of the order of $10 \mathrm{~km}$ (namely $8 \mathrm{~km}$ in this specific case), even with hydrostatic dynamics and parameterized convection, allows for an outstanding improvement of the rainfall intensity. Accumulated amounts well in excess of $200 \mathrm{~mm}$ in $36 \mathrm{~h}$ are simulated over the Apennines divide, affecting also the downstream catchments. The BOLAM simulation at low resolution (BOL-OLD, 20-km mesh) is hardly capable of producing the observed intensity of the heavy precipitation, although the secondary rainfall peak affects the Apennines crest and not just its upstream slopes and the coastal areas, as it was the case of the earlier simulations. Over the southeastern side of the Alps, both simulations capture the area of heavy precipitation, but BOL-OLD underestimates its extension and intensity.

Just to give a flavour of the extraordinary technological progress, which has been an important part of NWP development, the BOL-OLD 60-h simulation that was the best effort at the end of the 1990s, takes just few tens of second to run on an in-house Linux cluster.

To simulate more accurately the rainfall intensity on both the Alpine and Apennines reliefs, high resolution, convection-permitting simulations are actually required. MOLOCH largely improves the BOLAM QPF (compare Fig. 7 and Fig. 8): precipitation intensity is further increased on the Apennines crest as well as downstream, and the size of the mountainous area in southern Piedmont affected by heavy precipitation (values in excess of $200 \mathrm{~mm}$ ) is wider. Also, in better agreement with the observations, the area of moderate rainfall, oriented from
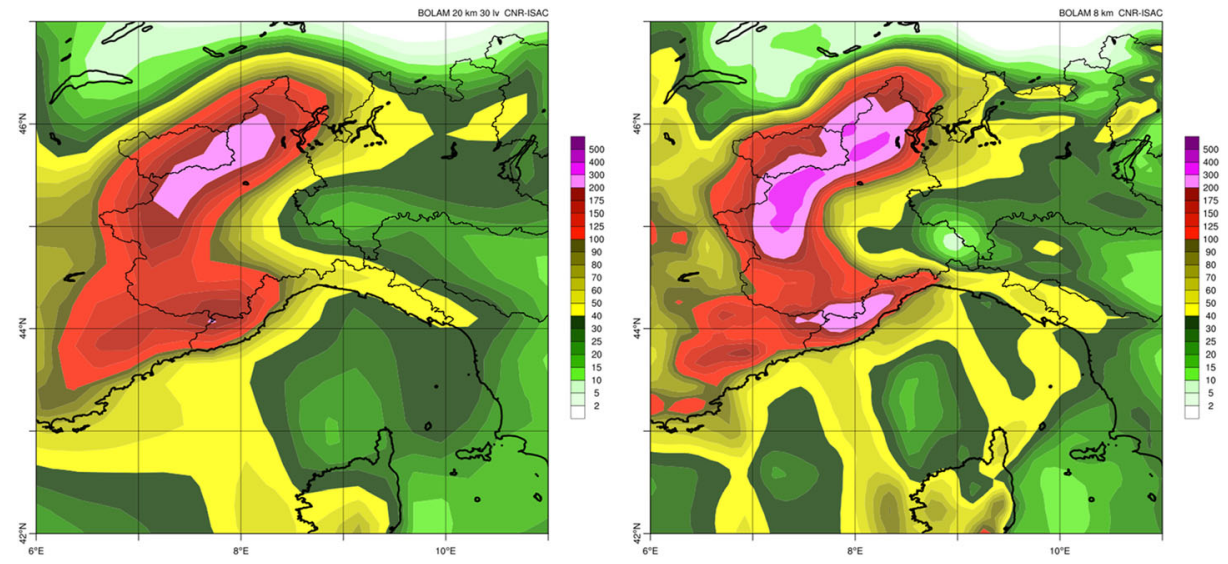

Fig. 7 36-h accumulated rainfall (colour bar in mm) from 1200 UTC, 04 November, to 0000 UTC, 06 November 1994 for (left) BOL-OLD and (right) BOL00 simulations. Bold black lines indicate land-sea mask, thin black lines indicate region administrative borders 

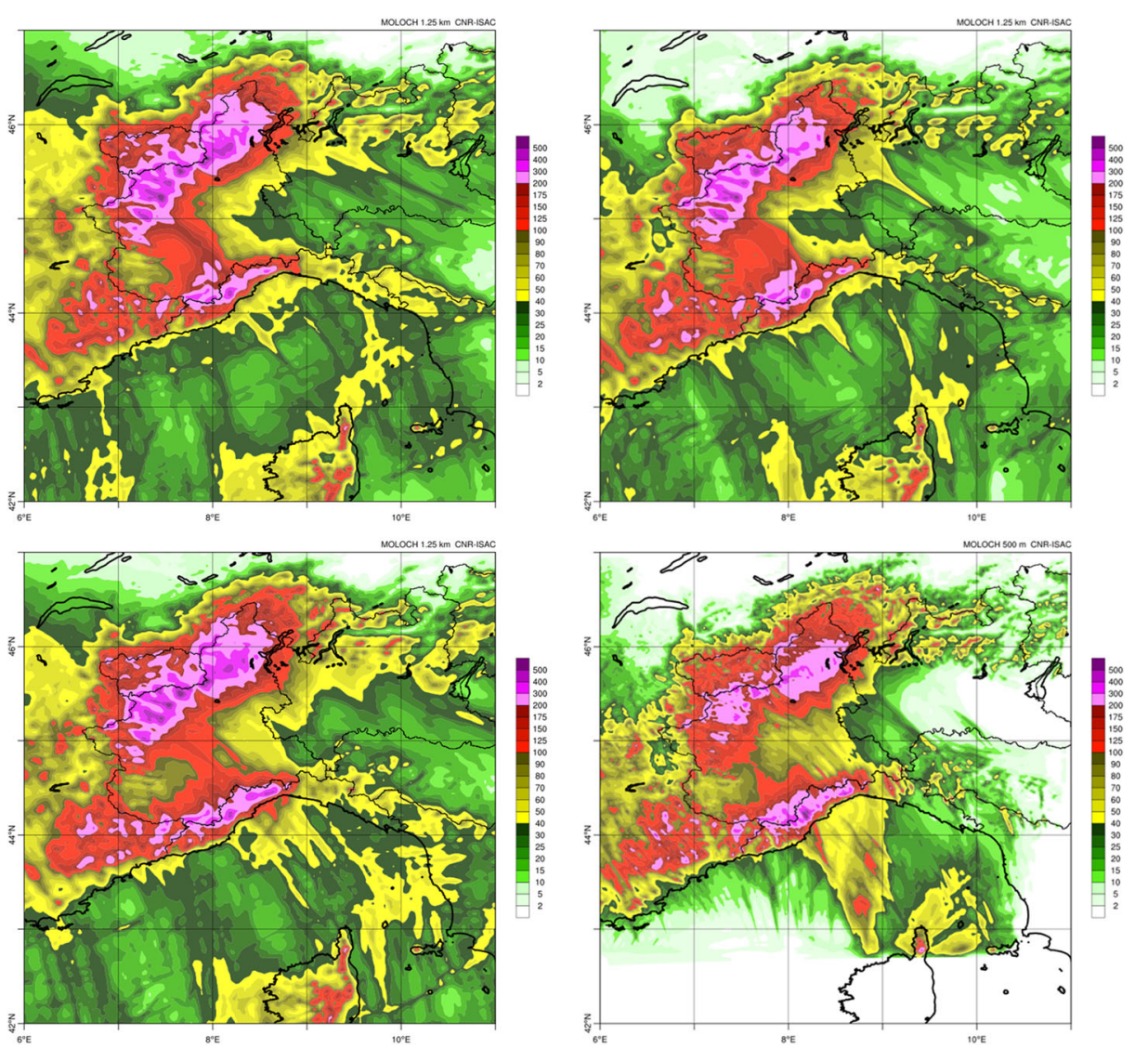

Fig. 8 36-h accumulated rainfall (colour bar in $\mathrm{mm}$ ) from 1200 UTC, 04 November, to 0000 UTC, 06 November 1994. Top-left: MOL00; bottom-left: MOL12; top-right: MOLexp; bottom-right: MOL500. Bold black lines indicate land-sea mask, thin black lines indicate region administrative borders

southeast to northwest, is reproduced over the plain area of Piedmont between the Apennines and the Alps, and the heavy precipitation exceeding $400 \mathrm{~mm}$ in $36 \mathrm{~h}$ is simulated over the Alpine orography.

The direct nesting of MOLOCH into the IFS forecast (Fig. 8) produces only minor changes in the simulated total rainfall, mainly in those areas where convection is more active. The modelling chain initialized $12 \mathrm{~h}$ later, BOL12 (not shown) and MOL12, provides a very similar simulation of the event (Fig. 8). Finally, the MOLOCH simulation at $500 \mathrm{~m}$ displays clearly the effect of the better-resolved orography and of the more accurate description of convective dynamics on the fine structure of the precipitation field. Over the Alpine region, total rainfall is slightly weaker compared with the other MOLOCH simulations, although still very intense. Over the Apennines the distribution is similar, but some localized peaks, possibly due to convection, appear more intense. Moreover, some areas of weak precipitation exhibit even less rainfall, as over the eastern Po Valley and over the sea. However, these differences are not only ascribable to the increased resolution, but also to the initial and boundary conditions and to the smaller integration domain. The latter has a clear impact on the development of convective cells over the sea, which can form only at some distance downstream from the southern border and are then advected towards the coast (as shown in Fig. 8, 
bottom-right panel). This represents a clear example of the importance of having a large enough inner domain when nesting a nonhydrostatic model into a larger scale one in which convection is parameterized, since instability of the incoming thermodynamic profiles has to be rebuilt. In the present application, the southern boundary seems far enough from the region of interest to allow at least the development of convection over the sea.

An in-depth and quantitative evaluation of the models performance is out of the scope of the present study. Moreover, in this respect, a single case study cannot provide statistically robust results, and the relatively small number of available observations poses limits to model output verification at small scales. However, a more detailed comparison among observed and forecast rainfall evolution, for selected representative rain gauge locations in the area, allows for highlighting some interesting characteristics of model simulations.

Three rain gauges located over the Alps and three over the Apennines are considered here. Observations are directly compared with model values on the closest grid point, with averages and intensity maxima within an area surrounding the station location. To this aim, an equal number of grid points surrounding that closest to the station is considered. For the $1.25 \mathrm{~km}(500 \mathrm{~m}) \mathrm{MOLOCH}$ simulations, this corresponds to a square region of about $15 \times 15(6 \times 6) \mathrm{km}$. The mean precipitation in the area is meant to account for unavoidable uncertainties in high resolution forecasting of convective events and, in principle, is more representative than a value sampled on a single grid point. However, given the large variability of rainfall intensity among neighbour grid points, to preserve the information about intense peaks smoothed out by averaging, a comparison is also shown for the grid point where accumulated precipitation is the largest in the $48 \mathrm{~h}$ period considered in the present analysis.

The observations at the three rain gauges over the Apennines (see their location in Fig. 3) clearly reflects the east-west gradient and the strong spatial variability of the rainfall field (Fig. 9), due to its convective nature. Weak precipitation (less than $100 \mathrm{~mm}$ in $48 \mathrm{~h}$ ) is recorded in the southwestern part of Piedmont, mainly during the final phase of the event, associated with the passage of the front. Moving
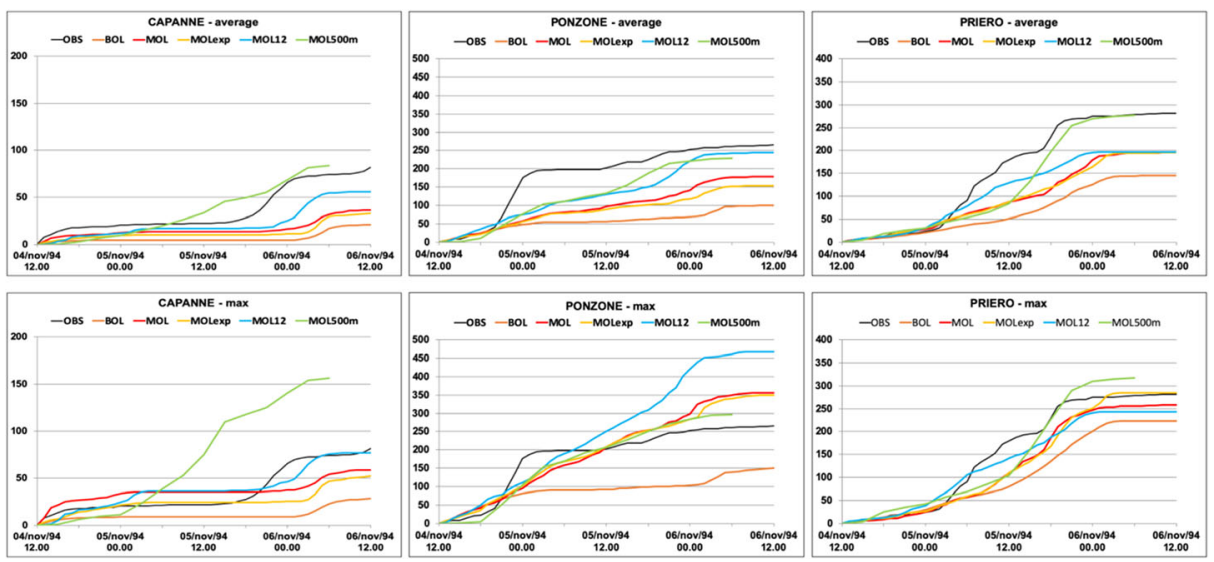

Fig. 9 Comparison between observed (black line) and simulated cumulated hourly rainfall at three rain gauges over the Apennines (see their location in Fig. 3), from 1200 UTC, 04 November, to 1200 UTC, 06 November 1994. Top: area average (see text) precipitation computed from the gridded model output for all simulations (see Table 1 for experiment acronyms). Bottom: model values at the grid point experiencing the maximum simulated rainfall in the 48 -h period 
eastward along the Apennines divide, precipitation intensity progressively increases, exceeding $250 \mathrm{~mm}$ in $48 \mathrm{~h}$. At the Ponzone rain gauge, most of the rainfall, about $150 \mathrm{~mm}$ in less than $6 \mathrm{~h}$, is due to a convective episode in the evening of 4 November. At Priero, less than $60 \mathrm{~km}$ to the west, rainfall starts later and seems to be characterized by several consecutive convective showers occurring until the evening of 5 November. The mean intensity provided by almost all model simulations underestimates the observed rainfall, but it is worth noting that forecasts are able to correctly display the characteristics of the rainfall fields described above. However, models hardly reproduce the sharp peak observed in Ponzone, where they forecast a more constant rainfall rate. As expected, BOLAM rainfall is systematically lower than that of MOLOCH. Variability is not particularly large among MOLOCH simulations, in agreement with the previous analysis of the rainfall fields, and seems primarily ascribable to the initial conditions. In fact, MOL and MOLexp experiments, both initialized at $0000 \mathrm{UTC}$, produce similar results, while MOL12, initialized $12 \mathrm{~h}$ later, is somehow different. MOLOCH simulation at $500 \mathrm{~m}$ performs best on average; although, it presents a remarkable local overestimation of the maximum precipitation at the easternmost rain gauge location (Capanne).

Simulation results are even closer to each other for the Alpine area (Fig. 10), and the averaged values still show a general underestimation of the observed rainfall, with MOL500 showing again the best performance in particular at Oropa. If maximum rainfall is considered, the agreement with observations increases, although, with some overestimations of the peaks (it is difficult to assess whether they are realistic or not, given the highly spatial variability). BOLAM is still not able to reproduce intense enough peaks, possibly because the uplift is weaker due to the limited orography resolution and because of the lack of explicit convection, which plays a role when convective cells are embedded in the stratiform orographic precipitation (Rotunno and Houze 2007). Over the Alps, the timing of the rainfall is well captured by all the experiments. Over this area, MOLOCH simulations, driven by ERA5 and BOLAM in cascade, are very close to each other regardless of the initialization time; although, MOLOCH simulation directly nested in the IFS forecast (MOLexp) produces slightly weaker precipitations. The large scale uplift due to the Alpine orography (as discussed
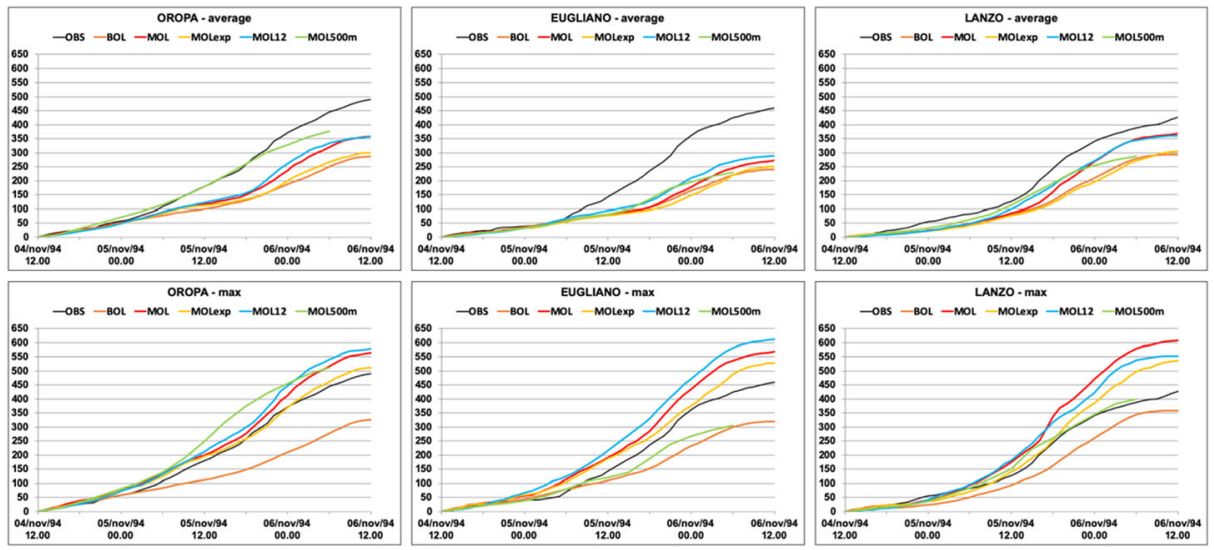

Fig. 10 Same as Fig. 9, but at the three rain gauges over the Alps (see their location Fig. 3) 
in Buzzi et al. 1998 and in Ferretti et al. 2000) provides increased predictability to the precipitation field, which is reflected by a smaller spread among the simulations. However, in terms of precipitation peaks, the differences between average and maximum precipitation within a limited area $(\mathrm{a}$ few $\mathrm{km}$ ) reveal a large variability of model results across neighbouring gridpoints.

\section{Convection over the Ligurian Sea and related mesoscale phenomena}

Recent studies in the framework of HyMeX, fostered by the occurrence of several dramatic flooding events over the Liguria region in the last 10 years, have identified a typical low-level wind configuration responsible for these heavy precipitation episodes (Buzzi et al. 2014; Fiori et al. 2017). In fact, the trigger and maintenance of intense prefrontal mesoscale convective systems close to the coastline have been ascribed to the convergence between a warm and moist southerly low-level jet over the sea and a cold air outflow from the Po Valley, across the Apennines gap to the Ligurian Sea. Along the convergence line that forms over the sea where these two flows collide, the continuous uplift of moisture laden air, above the leading edge of the shallow cold layer, can regenerate and feed convective cells for several hours. These cells, generated in almost the same location, then propagate with the mid-low tropospheric steering flow towards the Ligurian coast. Also the complex interaction with the coastal orography plays a role in modulating the persistence and location of these mesoscale convective systems. Already during the research activities following the MAP field campaign, this dynamics was partially observed and suggested by Bousquet and Smull (2003). However, only more recently, a clearer picture of the phenomenon was attained thanks also to high-resolution convection-permitting simulations.

In the studies that shortly followed the Piedmont flood, the main attention was devoted to analyse the role of the orographic forcing mainly in terms of direct uplift or partial blocking of the impinging flow, while indirect effects as that described above were not identified. It is therefore interesting to investigate whether the above dynamical features played a role in triggering convection over the sea, enhancing rainfall over the Ligurian Apennines, and to show to what extent a state-of-the-art NWP chain is able to reproduce them. Unfortunately, scarce remote sensing observations are available for that event, since the radar network was not operating yet. The only clue is the infrared satellite image, shown in Fig. 11, in which the typical pattern of a V-shape mesoscale convective system over the sea, affecting the Ligurian region, can be clearly identified, together with an intense convective activity developed over the northern tip of the Corsica Island.

All the numerical experiments generate a low-level wind convergence line just offshore the Liguria coastline, in a position suitable to explain the presence of the observed mesoscale convective system and compatible with the location of intense rainfall affecting the western part of the region. In fact, the forecast presented in Fig. 12 shows intense precipitation from the Apennines divide to the coast. The shape of the rainfall pattern, elongated over the sea, reveals the presence of the convergence line in the low levels. The convergence line is evident in Fig. 12, showing the 10-m wind field at 2100 UTC, 4 November, simulated by the MOL12 experiment. 


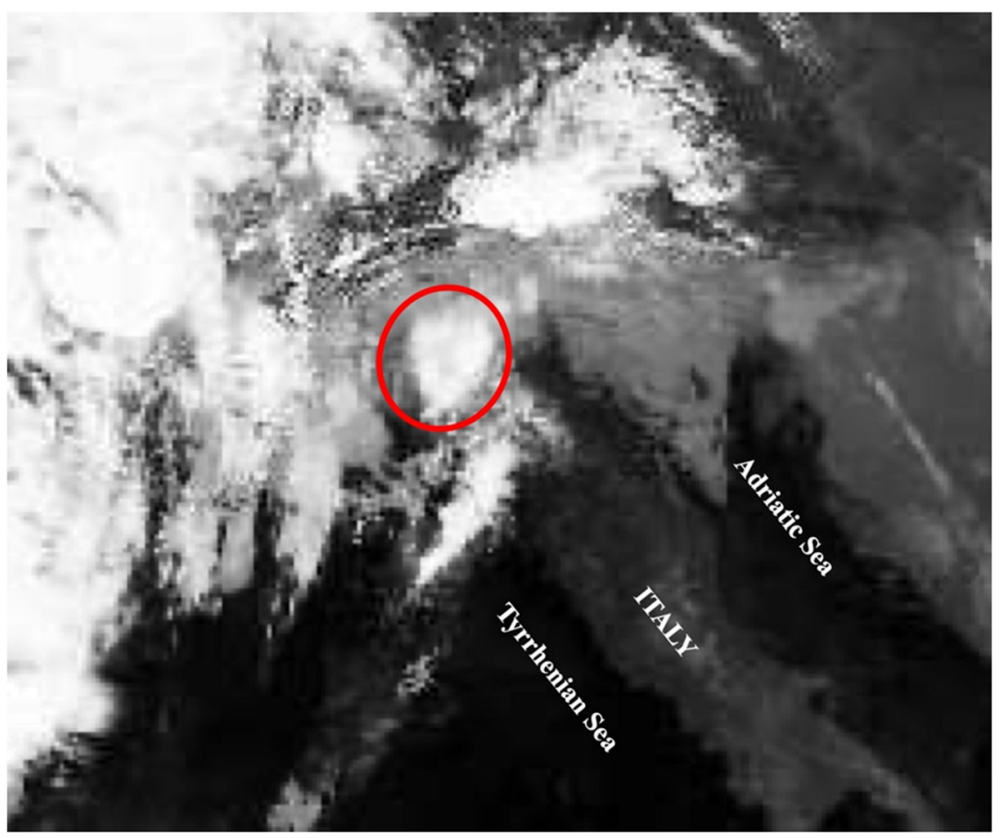

Fig. 11 NOAA-AVHRR IR images at 1941 UTC, 04 November 1994. The red circle indicates the V-shape MCS described in the text. The shape of the Italian peninsula is recognizable below the label "Italy"

Once the event proceeds, the approaching cold front determines an intensification of the southerly flows, so that the equilibrium along the convergence line is disrupted and the inflow from the sea is able to overcome the Apennines barrier, reaching the Alps.
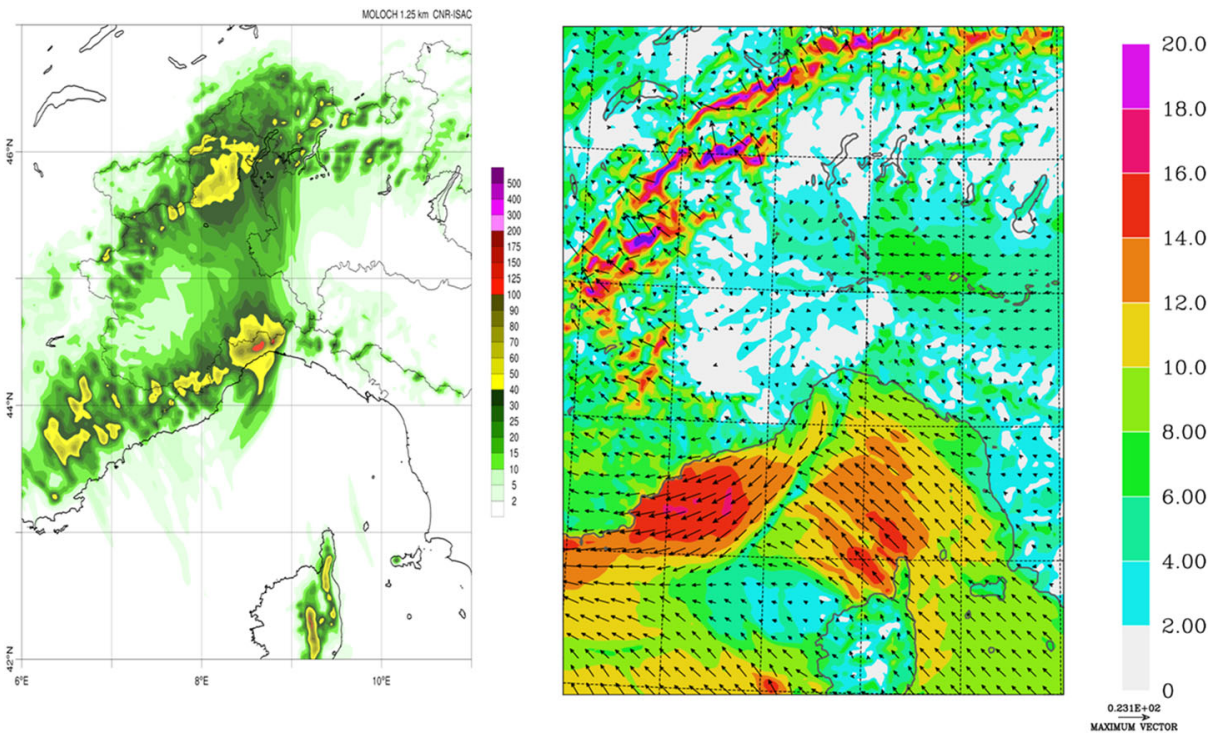

Fig. 12 (left) $12 \mathrm{~h}$ accumulated precipitation (experiment MOL12) between 1200 UTC, 04 November, and 0000 UTC, 05 November 1994 (colour bar in mm); (right) $10 \mathrm{~m}$ wind (colour bar in $\mathrm{ms}^{-1}$ ) at 2100 UTC, 04 November 1994 


\section{Conclusions}

The 25th anniversary of the infamous Piedmont flood of 1994 has been an opportunity to apply the modelling capabilities developed at CNR-ISAC to a high-impact meteorological and hydrological event that stimulated scientific research in the field of dynamic meteorology, numerical modelling and forecasting. Reexamining this extreme event in light of the current scientific knowledge and numerical modelling resources allows confirming and even deepening the results obtained about 20 years ago, and provides useful information for the current and future operational implementation of ISAC NWP models.

Simulation results based on multiple modelling tools interestingly indicate that this event is characterized by a relatively large predictability that goes, to some extent, into the subseasonal range. Moreover, they confirm the higher predictability of precipitation over the alpine slopes of Piedmont, while rainfall prediction over the Apennines, between Piedmont and Liguria, turns out to be more challenging due to the intense convective activity affecting this area, especially during the first phase of the event.

Convection-permitting model simulations successfully describe the mesoscale mechanisms leading to the formation and regeneration of convective systems offshore the Liguria coast, as well as their propagation to the north, leading to heavy precipitation over the Apennines divide, partly extending to the lee side areas corresponding to the Tanaro River catchment. These simulations, though still more or less underestimating precipitation peaks, provide a much more accurate rainfall prediction than up-do-date hydrostatic models, and demonstrate the capability to reproduce the observed very intense precipitation maxima at very high spatial resolution, i.e. in the subkilometre range. Most of the earlier hypotheses formulated about the possible causes of model errors (like limitations inherent in hydrostatic dynamics and of convective parameterization schemes, insufficient resolution in the presence of complex topography, simplified microphysics not describing advection of hydrometeors) have been confirmed after models have become by far more accurate. However, we do not intend to underestimate the importance of data assimilation and formulation of initial conditions: these crucial aspects of NWP would require a specific treatment and are out of the scope of the present paper.

For what concerns possible practical indications suggested by this study, the recently adopted operational setup based entirely on ISAC models, namely the application in cascade of GLOBO, BOLAM and MOLOCH, is somehow supported by the results of this case study, but may need further investigation. Moreover, even the direct nesting of MOLOCH into the global IFS analysis and forecast fields seems feasible since it is not affected by relevant noise propagation, neither due to the initial condition nor at the boundaries. However, when implementing a modelling chain over an area such as the Mediterranean basin, and in particular Italy that is characterized by complex orography and sea-land transition, the choice of the integration domain is critical. These simulation results, as well as the expertise after many years of NWP practise, suggest that this aspect is at least as important as model resolution, and thus it requires particular attention.

Acknowledgements This work was supported by the Civil Protection of Italy under contract "Intesa Operativa con CNR-ISAC". This work is a contribution to the HyMeX international programme. We thank ARPA Piemonte for providing rain gauge data and the observed rainfall Fig. 1. This work has been written during the time of the COVID 19-we wish to thank the physicians and nurses who risk their lives every day in these difficult times. 


\section{References}

Bacchi B, Ranzi R (2000) Runoff and atmospheric processes for flood hazard forecasting and control. In: Final report contract ENV4-CT97-0552, Brescia

Bougeault P, Binder P, Buzzi A, Dirks R, Kuettner J, Smith RB, Steinacker R, Volkert H (2001) The MAP special observing period. Bull Amer Meteor Soc 82:433-462. https://doi.org/10.1175/1520-0477(2001)082 $<0433$ :TMSOP>2.3.CO;2

Bousquet O, Smull BF (2003) Observations and impacts of upstream blocking during a widespread orographic precipitation event. Quart J Roy Meteor Soc 129:391-409

Branković Č, Molteni F (1997) Sensitivity of the ECMWF model northern winter climate to model formulation. Clim Dyn 13:75-101

Buzzi A, Fantini M, Malguzzi P, Nerozzi F (1994) Validation of a limited area model in cases of Mediterranean cyclogenesis: surface fields and precipitation scores. Meteor Atmos Phys 53:137-153

Buzzi A, Tartaglione N, Malguzzi P (1998) Numerical simulations of the 1994 Piedmont flood: role of orography and moist processes. Mon Wea Rev 126:2369-2383

Buzzi A, Foschini L (2000) Mesoscale meteorological features associated with heavy precipitation in the southern Alpine region. Meteor Atmos Phys 72:131-146

Buzzi A, D'Isidoro M, Davolio S (2003) A case study of an orographic cyclone formation south of the Alps during the MAP-SOP. Quart J Roy Meteor Soc 129:1795-1818

Buzzi A, Davolio S, Malguzzi P, Drofa O, Mastrangelo D (2014) Heavy rainfall episodes over Liguria of autumn 2011: numerical forecasting experiments. Nat Hazards Earth Syst Sci 14:1325-1340. https://doi.org/10.5194 /nhess-14-1325-2014

Buzzi A, Di Muzio E, Malguzzi P (2020) Barrier wind in the Italian region and effects of moist processes. Bulletin of Atmospheric Science and Technology 1:59-90. https://doi.org/10.1007/s42865-020-00005-6

C3S Copernicus Climate Change Service (2017) ERA5: fifth generation of ECMWF atmospheric reanalyses of the global climate. Climate Data Store (CDS), last access: 13 March 2020. https://cds.climate.copernicus. eu/cdsapp\#!/home

Casaioli M, Mariani S, Malguzzi P, Speranza A (2013) Factors affecting the quality of QPF: a multi-method verification of multi-configuration BOLAM reforecasts against MAP D-PHASE observations. Meteor Appl 20:150-163

Cassardo C, Loglisci N, Gandini D, Qian MW, Niu GY, Ramieri P, Pelosini R, Longhetto A (2002) The flood of November 1994 in Piedmont, Italy: a quantitative analysis and simulation. Hydrol Process 16:1275-1299

Cavaleri L, Bertotti L, Buizza R, Buzzi A, Masato V, Umgiesser G, Zampieri M (2010) Predictability of extreme meteo-oceanographic events in the Adriatic Sea. Quart J Roy Meteor Soc 136:400-413

Chiao S, Lin YL, Kaplan ML (2004) Numerical study of orographic forcing of heavy orographic precipitation during MAP IOP 2B. Mon Wea Rev 132:2184-2203

Cioni G, Malguzzi P, Buzzi A (2016) Thermal structure and dynamical precursor of a Mediterranean tropical-like cyclone. Quart J Roy Meteor Soc 142:1757-1766

Corazza M, Sacchetti D, Antonelli M, Drofa O (2018) The ARPAL operational high resolution poor man's ensemble, description and validation. Atmos Res 203:1-15

Davolio S, Buzzi A, Malguzzi P (2009) Orographic triggering of long-lived convection in three dimensions. Meteor Atmos Phys 103:35-44

Davolio S, Silvestro F, Malguzzi P (2015) Effects of increasing horizontal resolution in a convection permitting model on flood forecasting: the 2011 dramatic events in Liguria (Italy). J Hydrometeorol 16:1843-1856

Davolio S, Volontè A, Manzato A, Pucillo A, Cicogna A, Ferrario ME (2016) Mechanisms producing different precipitation patterns over north-eastern Italy: insights from HyMeX-SOP1 and previous events. Quart J Roy Meteor Soc 142:188-205

Davolio S, Henin R, Stocchi P, Buzzi A (2017a) Bora wind and heavy persistent precipitation: atmospheric water balance and role of air-sea fluxes over the Adriatic Sea. Quart J Roy Meteor Soc 143:1165-1177. https://doi. org/10.1002/qj.3002

Davolio S, Silvestro F, Gastaldo T (2017b) Impact of rainfall assimilation on high-resolution hydro-meteorological forecasts over Liguria (Italy). J Hydrometeorol 18:2659-2680

Dee DP, Uppala SM, Simmons AJ, Berrisford P, Poli P, Kobayashi S, Andrae U, Balmaseda MA, Balsamo G, Bauer P, Bechtold P, Beljaars ACM, van de Berg L, Bidlot J, Bormann N, Delsol C, Dragani R, Fuentes M, Geer AJ, Haimberger L, Healy SB, Hersbach H, Hólm EV, Isaksen L, Kållberg P, Köhler M, Matricardi M, McNally AP, Monge-Sanz BM, Morcrette JJ, Park BK, Peubey C, de Rosnay P, Tavolato C, Thépaut JN, Vitart F (2011) The ERA-interim reanalysis: configuration and performance of the data assimilation system. Quart J Roy Meteor Soc 137:553-597. https://doi.org/10.1002/qj.828

Drobinski P, Ducrocq V, Alpert P, Anagnostou E, Béranger K, Borga M, Braud I, Chanzy A, Davolio S, Delrieu G, Estournel C, Boubrahmi NF, Font J, Grubišić V, Gualdi S, Homar V, Ivančan-Picek B, Kottmeier C, 
Kotroni V, Lagouvardos K, Lionello P, Llasat MC, Ludwig W, Lutoff C, Mariotti A, Richard E, Romero R, Rotunno R, Roussot O, Ruin I, Somot S, Taupier-Letage I, Tintore J, Uijlenhoet R, Wernli H (2014) HyMeX, a 10-year multidisciplinary program on the Mediterranean water cycle. Bull Am Meteor Soc 95: 1063-1082

Ducrocq V, Braud I, Davolio S, Ferretti R, Flamant C, Jansa A, Kalthoff N, Richard E, Taupier-Letage I, Ayral PA, Belamari S, Berne A, Borga M, Boudevillain B, Bock O, Boichard JL, Bouin MN, Bousquet O, Bouvier C, Chiggiato J, Cimini D, Corsmeier U, Coppola L, Cocquerez P, Defer E, Delanoë J, di Girolamo P, Doerenbecher A, Drobinski P, Dufournet Y, Fourrié N, Gourley JJ, Labatut L, Lambert D, le Coz J, Marzano FS, Molinié G, Montani A, Nord G, Nuret M, Ramage K, Rison W, Roussot O, Said F, Schwarzenboeck A, Testor P, van Baelen J, Vincendon B, Aran M, Tamayo J (2014) HyMeX-SOP1, the field campaign dedicated to heavy precipitation and flash flooding in the northwestern Mediterranean. Bull Am Meteor Soc 95:1083-1100

Fantini M, Malguzzi P (2008) Numerical study of two-dimensional moist symmetric instability. Adv Geosci 17: 1-4

Fantini M, Malguzzi P, Buzzi A (2012) Numerical study of slantwise circulations in a strongly-sheared prefrontal environment. Quart J Roy Meteor Soc 138:585-595

Ferrarin C, Bajo M, Roland A, Umgiesser G, Cucco A, Davolio S, Buzzi A, Malguzzi P, Drofa O (2013) Tidesurge-wave modelling and forecasting in the Mediterranean Sea with focus on the Italian coast. Ocean Model 61:38-48

Ferrarin C, Davolio S, Bellafiore D, Ghezzo M, Maicu F, Mc Kiver W, Drofa O, Umgiesser G, Bajo M, De Pascalis F, Malguzzi P, Zaggia L, Lorenzetti G, Manfè G (2019) Cross-scale operational oceanography in the Adriatic Sea. J of Operational Oceanography 12(2):86-103

Ferretti R, Low-Nam S, Rotunno R (2000) Numerical simulations of the Piedmont flood of 4-6 November 1994. Tellus A 52:162-180

Ferretti R, Pichelli E, Gentile S, Maiello I, Cimini D, Davolio S, Miglietta MM, Panegrossi G, Baldini L, Pasi F, Marzano FS, Zinzi A, Mariani S, Casaioli M, Bartolini G, Loglisci N, Montani A, Marsigli C, Manzato A, Pucillo A, Ferrario ME, Colaiuda V, Rotunno R (2014) Overview of the first HyMeX special observation period over Italy: observations and model results. Hydrol Earth Syst Sci 18:1953-1977

Fiori E, Ferraris L, Molini L, Siccardi F, Kranzlmueller D, Parodi A (2017) Triggering and evolution of a deep convective system in the Mediterranean Sea: modelling and observations at a very fine scale. Quart J Roy Meteor Soc 143:927-941

Grazzini F, Craig CG, Keil C, Antolini G, Pavan V (2020) Extreme precipitation events over northern Italy. Part I: a systematic classification with machine-learning techniques. Quart J Roy Meteor Soc 146:69-85. https://doi.org/10.1002/qj.3635

Hersbach H, Dee D (2016) ERA5 reanalysis is in production. ECMWF Newsletter 147:7 https://www.ecmwf. int/en/newsletter/147/news/era5-reanalysis-production

Hubbard ME, Nikiforakis N (2003) A three-dimensional adaptive, Godunov type model for global atmospheric flows I: tracer advection on fixed grids. Mon Wea Rev 131:1848-1864

Kain JS (2004) The Kain-Fritsch convective parameterization: an update. J Appl Meteorol 43:170-181. https://doi.org/10.1175/1520-0450(2004)043<0170:TKCPAU>2.0.CO;2

Lagouvardos K, Kotroni V, Koussis A, Feidas C, Buzzi A, Malguzzi P (2003) The meteorological model BOLAM at the National Observatory of Athens: assessment of two-year operational use. J Appl Meteorol 42:1667-1678

Lalas DP, Einaudi F (1974) On the correct use of the wet adiabatic lapse rate in stability criteria of a saturated atmosphere. J Appl Meteorol 13:318-324

Lascaux F, Richard E, Pinty JP (2006) Numerical simulations of three different MAP IOPs and the associated microphysical processes. Quart J Roy Meteor Soc 132:1907-1926

Lee KO, Flamant C, Duffourg F, Ducrocq V, Chaboureau JP (2018) Impact of upstream moisture structure on a back-building convective precipitation system in South-Eastern France during HyMeX IOP13. Atmos Chem Phys 18:16845-16862

Lombardi G, Ceppi A, Ravazzani G, Davolio S, Mancini M (2018) From deterministic to probabilistic forecasts: the 'Shift-Target' approach in the Milan urban area (Northern Italy). Geosciences 8(5):181

Malguzzi P, Grossi G, Buzzi A, Ranzi R, Buizza R (2006) The 1966 'century' flood in Italy: a meteorological and hydrological revisitation. J Geophys Res 111:D24106

Malguzzi P, Buzzi A, Drofa O (2011) The meteorological global model GLOBO at the ISAC-CNR of Italy: assessment of 1.5 years of experimental use for medium range weather forecast. Weather Forecast 26:1045-1055

Mastrangelo D, Malguzzi P, Rendina C, Drofa O, Buzzi A (2012) First outcomes from the CNR-ISAC monthly forecasting system. Adv Sci Res 8:77-82. https://doi.org/10.5194/asr-8-77-2012

Mastrangelo D, Malguzzi P (2019) Verification of two years of CNR-ISAC subseasonal forecasts. Weather Forecast 34:331-344 
Mariani S, Casaioli M, Coraci E, Malguzzi P (2015) New high-resolution BOLAM-MOLOCH suite for the SIMM forecasting system: assessment over two HyMeX intense observation periods. Nat Hazards Earth Sys Sci 15:1-24

Massacand AC, Wernli H, Davies HC (1998) Heavy precipitation on the Alpine Southside: an upper-level precursor. Geophys Res Let 25(9):1435-1438. https://doi.org/10.1029/98GL50869

Morcrette JJ, Barker HW, Cole JNS, Iacono MJ, Pincus R (2008) Impact of a new radiation package, McRad, in the ECMWF integrated forecasting system. Mon Wea Rev 136:4773-4798. https://doi.org/10.1175/2008 MWR2363.1

Nagata M, Leslie L, Kamahori H, Nomura R, Mino H, Kurihara Y, Rogers E, Elsberry RL, Basu BK, Buzzi A, Calvo J, Desgagné M, D’Isidoro M, Hong SY, Katzfey J, Majewski D, Malguzzi P, McGregor J, Murata A, Nachamkin J, Roch M, Wilson C (2001) A mesoscale model intercomparison: a case of explosive development of a tropical cyclone (COMPARE III). J Meteor Soc Japan Ser II 79(5):999-1033

Pichelli E, Rotunno R, Ferretti R (2017) Effects of the Alps and Apennines on forecasts for Po Valley convection in two HyMeX cases. Quart J Roy Meteor Soc 143:2420-2435

Poletti ML, Silvestro F, Davolio S, Pignone F, Rebora N (2019) Using nowcasting technique and data assimilation in a meteorological model to improve very short range hydrological forecasts. Hydrol Earth Sys Sci 23:3823-3841

Richard E, Buzzi A, Zängl G (2007) Quantitative precipitation forecasting in the Alps: the advances achieved by the Mesoscale Alpine Programme. Quart J Roy Meteor Soc 133:831-846

Ritter B, Geleyn JF (1992) A comprehensive radiation scheme for numerical weather prediction models with potential applications in climate simulations. Mon Wea Rev 120:303-325. https://doi.org/10.1175/15200493(1992)120<0303:ACRSFN>2.0.CO;2

Rotach MW, Ambrosetti P, Ament F, Appenzeller C, Arpagaus M, Bauer HS, Behrendt A, Bouttier F, Buzzi A, Corazza M, Davolio S, Denhard M, Dorninger M, Fontannaz L, Frick J, Fundel F, Germann U, Gorgas T, Hegg C, Hering A, Keil C, Liniger MA, Marsigli C, McTaggart-Cowan R, Montaini A, Mylne K, Ranzi R, Richard E, Rossa A, Santos-Muñoz D, Schär C, Seity Y, Staudinger M, Stoll M, Volkert H, Walser A, Wang Y, Werhahn J, Wulfmeyer V, Zappa M (2009) MAP D-PHASE: real-time demonstration of weather forecast quality in the Alpine region. Bull Am Meteor Soc 90:1321-1336

Rotunno R, Houze RA (2007) Lessons on orographic precipitation from the Mesoscale Alpine Programme. Quart J Roy Meteor Soc 133:811-830

Rotunno R, Ferretti R (2001) Mechanisms of intense Alpine rainfall. J Atmos Sci 58:1732-1749

1Rotunno R, Ferretti R (2003) Orographic effects on rainfall in MAP cases IOP 2b and IOP 8. Quart J Roy Meteor Soc 129:373-390

Tiesi A, Miglietta MM, Conte D, Drofa O, Davolio S, Malguzzi P, Buzzi A (2016) Heavy rain forecasting by model initialization with LAPS: a case study. IEEE Journal of Selected Topics in Applied Earth Observations and Remote Sensing 9(6):2619-2627

Uboldi F, Trevisan A (2015) Multiple-scale error growth in a convection-resolving model. Nonlinear Process Geophys 22:1-13

Trini Castelli S, Bisignano A, Donateo A, Landi TC, Martano P, Malguzzi P (2020) Evaluation of the turbulence parametrization in the MOLOCH meteorological model. Quart J Roy Meteor Soc 146:124-140. https://doi. org/10.1002/qj.3661

Vitart F, Ardilouze C, Bonet A, Brookshaw A, Chen M, Codorean C, Déqué M, Ferranti L, Fucile E, Fuentes M, Hendon H, Hodgson J, Kang HS, Kumar A, Lin H, Liu G, Liu X, Malguzzi P, Mallas I, Manoussakis M, Mastrangelo D, MacLachlan C, McLean P, Minami A, Mladek R, Nakazawa T, Najm S, Nie Y, Rixen M, Robertson AW, Ruti P, Sun C, Takaya Y, Tolstykh M, Venuti F, Waliser D, Woolnough S, Wu T, Won DJ, Xiao H, Zaripov R, Zhang L (2017) The subseasonal to seasonal (S2S) prediction project database. Bull Am Meteor Soc 98:163-173

Vitart F et al (2019) Sub-seasonal to seasonal prediction of weather extremes. In: Robertson a W, Vitart F (ed) subseasonal to seasonal prediction: the gap between weather and climate forecasting, 1st edn. Elsevier, pp 365-386

Volkert H (2000) Heavy precipitation in the Alpine region (HERA): areal rainfall determination for flood warnings through in-situ measurements, remote sensing and atmospheric modelling. Meteor Atmos Phys 72:73-85

White CJ, Carlsen H, Robertson AW, Klein RJT, Lazo JK, Kumar A, Vitart F, Coughlan de Perez E, Ray AJ, Murray V, Bharwani S, MacLeod D, James R, Fleming L, Morse AP, Eggen B, Graham R, Kjellström E, Becker E, Pegion KV, Holbrook NJ, McEvoy D, Depledge M, Perkins-Kirkpatrick S, Brown TJ, Street R, Jones L, Remenyi TA, Hodgson-Johnston I, Buontempo C, Lamb R, Meinke H, Arheimer B, Zebiak SE (2017) Potential applications of subseasonal-to-seasonal (S2S) predictions. Meteor Appl 24:315-325

Zampieri M, Malguzzi P, Buzzi A (2005) Sensitivity of quantitative precipitation forecasts to boundary layer parameterization: a flash flood case study in the western Mediterranean. Nat Hazards Earth Syst Sci 5:603-612 